\title{
Dietary Supplement Use and Colorectal Adenoma Risk in Individuals with Lynch Syndrome: The GEOLynch Cohort Study
}

\author{
Renate C. Heine-Bröring ${ }^{1}$, Renate M. Winkels ${ }^{1}$, Akke Botma', Fränzel J. B. van Duijnhoven ${ }^{1,2}$, \\ Audrey Y. Jung ${ }^{3}$, Jan H. Kleibeuker ${ }^{4}$, Fokko M. Nagengast ${ }^{5}$, Hans F. A. Vasen ${ }^{6}$, Ellen Kampman ${ }^{1,3,7 *}$ \\ 1 Division of Human Nutrition, Wageningen University, Wageningen, The Netherlands, 2 National Institute for Public Health and the Environment (RIVM), Bilthoven, The \\ Netherlands, 3 Department of Epidemiology, Biostatistics, and HTA, Radboud University Nijmegen Medical Centre, Nijmegen, The Netherlands, 4 Department of \\ Gastroenterology, University Medical Center Groningen, University of Groningen, Groningen, The Netherlands, 5 Department of Gastroenterology, Radboud University \\ Nijmegen Medical Centre, Nijmegen, The Netherlands, $\mathbf{6}$ Netherlands Foundation for the Detection of Hereditary Tumours, Leiden, The Netherlands, 7 Department for \\ Health Sciences, VU University Amsterdam, Amsterdam, The Netherlands
}

\begin{abstract}
Background and Aims: Individuals with Lynch syndrome have a high lifetime risk of developing colorectal tumors. In this prospective cohort study of individuals with Lynch syndrome, we examined associations between use of dietary supplements and occurrence of colorectal adenomas.

Materials and Methods: Using data of 470 individuals with Lynch syndrome in a prospective cohort study, associations between dietary supplement use and colorectal adenoma risk were evaluated by calculating hazard ratios (HR) and $95 \%$ confidence intervals $(\mathrm{Cl})$ using cox regression models adjusted for age, sex, and number of colonoscopies during person time. Robust sandwich covariance estimation was used to account for dependency within families.

Results: Of the 470 mismatch repair gene mutation carriers, 122 (26.0\%) developed a colorectal adenoma during an overall median person time of 39.1 months. $40 \%$ of the study population used a dietary supplement. Use of any dietary supplement was not statistically significantly associated with colorectal adenoma risk ( $\mathrm{HR}=1.18 ; 95 \% \mathrm{Cl} 0.80-1.73)$. Multivitamin supplement use $(\mathrm{HR}=1.15 ; 95 \% \mathrm{Cl} 0.72-1.84)$, vitamin $\mathrm{C}$ supplement use $(\mathrm{HR}=1.57 ; 95 \% \mathrm{Cl} 0.93-2.63)$, calcium supplement use $(\mathrm{HR}=0.69 ; 95 \% \mathrm{Cl} 0.25-1.92)$, and supplements containing fish oil $(\mathrm{HR}=1.60 ; 95 \% \mathrm{Cl} 0.79-3.23)$ were also not associated with occurrence of colorectal adenomas.

Conclusion: This prospective cohort study does not show inverse associations between dietary supplement use and occurrence of colorectal adenomas among individuals with Lynch syndrome. Further research is warranted to determine whether or not dietary supplement use is associated to colorectal adenoma and colorectal cancer risk in MMR gene mutation carriers.
\end{abstract}

Citation: Heine-Bröring RC, Winkels RM, Botma A, van Duijnhoven FJB, Jung AY, et al. (2013) Dietary Supplement Use and Colorectal Adenoma Risk in Individuals with Lynch Syndrome: The GEOLynch Cohort Study. PLoS ONE 8(6): e66819. doi:10.1371/journal.pone.0066819

Editor: Jung Eun Lee, Sookmyung Women's University, Republic Of Korea

Received January 24, 2013; Accepted May 10, 2013; Published June 18, 2013

Copyright: (c) 2013 Heine-Bröring et al. This is an open-access article distributed under the terms of the Creative Commons Attribution License, which permits unrestricted use, distribution, and reproduction in any medium, provided the original author and source are credited.

Funding: This work was financially supported by the Dutch Cancer Society (grant UW-2005-3275); Wereld Kanker Onderzoek Fonds (WCRF NL); and World Cance Research Fund International (WCRF International). Websites: (http://dcs.kwfkankerbestrijding.nl/Pages/Home.aspx.) (http://www.wcrf.nl/). (http://www.wcrf.org/) The funders had no role in study design, data collection and analysis, decision to publish, or preparation of the manuscript.

Competing Interests: The authors have declared that no competing interests exist.

*E-mail: Ellen.Kampman@wur.nl

\section{Introduction}

Individuals with Lynch syndrome have pathogenic germline mutations in genes involved in DNA mismatch repair (MMR), i.e. MLH1, MSH2, MSH6, PMS2, [1-5] or in the EPCAM gene. $[6,7]$ Approximately 3\% of all colorectal cancers are induced by Lynch syndrome. [8,9] The adenoma-carcinoma sequence seems to be accelerated in MMR gene mutation carriers, [10] and carriers have a $25-70 \%$ risk of developing colorectal cancer up to age 70 , at a relatively young age, $[2-5,11]$ compared to $2-5 \%$ in the general Western population. [12,13]

Removal of colorectal adenomas lowers risk of colorectal carcinomas in individuals with Lynch syndrome. [14,15] There- fore, those persons are generally advised to follow strict periodic endoscopic surveillance to detect colorectal adenomas. $[15,16]$ Considering the high lifetime risk of developing adenomas and carcinomas in MMR gene mutation carriers, [2-5] it is very relevant to study whether modifiable lifestyle factors, including dietary supplement use, can affect this risk. As shown in previous studies from our group, excess body weight, [17] smoking, [18] and a dietary pattern high in snack foods [19] were associated with an increased risk of colorectal adenomas in persons with Lynch syndrome. Retrospective case-control studies in Lynch syndrome suspected-families showed that increased fruit consumption and dietary fibre intake possibly decreased the risk of colorectal tumors. [20] 
Although a healthy diet provides a sufficient amount of vitamins and minerals, many individuals take vitamin and mineral supplements regularly, hoping to further improve their health and to prevent acute or chronic illnesses and serious diseases, such as cancer. [21,22] Dietary supplement use and colorectal adenoma risk have been extensively investigated in the general population. No convincing evidence for an association between multivitamin supplement use, [23] folic acid supplement use, [24] and antioxidant supplement use and adenoma occurrence was found, $[25,26]$ whereas calcium supplement use might contribute to a lower risk of colorectal adenomas. [27] MMR gene mutation carriers might have a higher use of dietary supplements compared to the general Dutch population based on their health status and risk. [28] Up until now, as far as we know, no studies on dietary supplement use and colorectal adenomas among individuals with Lynch syndrome were conducted.

The objective of this study was to prospectively examine the association between the most frequently used dietary supplements and colorectal adenoma development in a cohort study of individuals with Lynch syndrome.

\section{Materials and Methods}

\section{Ethics Statement}

The Medical Ethics Committee of the Radboud University Nijmegen Medical Centre approved the study. All participants gave written informed consent.

\section{Study population}

Individuals with Lynch syndrome participated in the GEOLynch prospective cohort study which was described earlier. [17] Briefly, carriers of a germline mutation in at least one of the mismatch repair genes were identified via linkage to a hereditary tumor registration of the Netherlands Foundation for the Detection of Hereditary Tumors in Leiden, the Radboud University Nijmegen Medical Center in Nijmegen, and the University Medical Center Groningen in Groningen, the Netherlands. Participants had to be between 18 and 80 years of age, Dutch-speaking, white, and mentally competent to participate in this study to be eligible for the study. Terminally ill patients, and those with familial adenomatous polyposis, inflammatory bowel diseases, a complete proctocolectomy or colostomy were excluded.

With approval of their medical specialist, a total of 713 mutation carriers were invited to participate in the study between July 2006 and July 2008. Six hundred ninety-five out of 713 people could be contacted of whom nine were ineligible. Of these, $73 \%$ (499 of 686) agreed to participate. We were unable to retrieve medical and personal information from 29 participants. Therefore, a total of 470 participants from at least 161 families were included in this study.

\section{Exposure assessment}

At recruitment, dietary supplement use was collected using a self-administered questionnaire. Information on dietary supplement use included frequency of intake (no intake in the previous month, once a month, 2-3 days a month, once a week, 2-3 days a week, 4-5 days a week, 6-7 days a week), amount of intake (1, 2, 3, 4 , or $\geq 5$ tablets, capsules or droplets), and brand name of multivitamins, vitamin $\mathrm{C}, \mathrm{B}$-vitamins, folic acid, vitamin $\mathrm{D}$ (including vitamin A), vitamin E, calcium, iron, and fish oil supplements. In addition, participants could indicate whether they used other supplements that were not covered by the questionnaire. In this study, users of dietary supplements were defined as those taking any dietary supplement during the last month. When patients took no dietary supplements at all during the last month, they were considered nonusers. Habitual dietary intake was collected using a 183-item self-administered and validated food frequency questionnaire. [29,30] General lifestyle information was collected with a lifestyle questionnaire containing questions about age, sex, weight, height, smoking habits, medication use, physical activity,[31] family history of colorectal cancer, and medical history.

\section{Outcome data}

Medical information, including information about medical history and colorectal adenomas and carcinomas, was obtained by reviewing medical records regularly from all subjects via the participating centers until information was complete. From every participant, information about previously performed colonoscopies, colorectal surgery, cancer, and adenomatous polyps was gathered before recruitment and during follow up until December 31, 2010. We ascertained detailed information from pathology reports about location, size, and histology for all documented colorectal adenomas that occurred during follow up.

\section{Data analysis}

The outcome of our analysis was the time to diagnosis of the first pathology-confirmed colorectal adenoma. Descriptive statistics were used to describe the demographic characteristics, and characteristics on lifestyle, medical status, dietary supplement use and dietary intake of all $470 \mathrm{MMR}$ gene mutation carriers and from those who were diagnosed with a colorectal adenoma during follow up. In addition, general characteristics were computed for dietary supplement users versus nonusers. Differences in baseline characteristics between users and non-users were tested by the Mann-Whitney $U$ test (continuous variables) or the $\chi^{2}$ test (categorical variables).

Cox proportional hazards regression was used to investigate associations of dietary supplement use and colorectal adenoma occurrence. Hazard ratios (HR) with 95\% confidence intervals $(95 \%$ CI $)$ were reported, and robust sandwich covariance estimation was used to account for dependency of observations within families. The Cox proportional hazard models were tested for and met the assumption of proportionality by visually inspecting whether the distance between the $\log (-\log )$ survival curves was approximately constant. Person time started at the date of the most recent colonoscopy before assessment of dietary supplement use and ended at the date of colonoscopy of the first diagnosed colorectal adenoma during follow up. Participants without a colorectal adenoma diagnosis or without a detectable colorectal adenoma were censored at the date of their last known colonoscopy during follow up.

The following covariates were evaluated as potentially confounding variables: age (continuous), sex, educational level (categorical: high vs lower educated), number of colonoscopies during person time (continuous), history of colorectal adenomas (yes/no), history of carcinomas (yes/no), physical activity level (categorical: high vs lower physically active), smoking status (current, former, never), body mass index (continuous), regular use of NSAIDs ( $<1$ times/week, $\geq 1$ times/week), alcohol intake $(\mathrm{g} / \mathrm{d})$, total energy intake $(\mathrm{kJ} / \mathrm{d})$, total vegetables intake $(\mathrm{g} / \mathrm{d})$, total fruit intake $(\mathrm{g} / \mathrm{d})$, and total red meat intake $(\mathrm{g} / \mathrm{d})$. In the basic model, we adjusted for age and sex. Covariates were considered as confounders if they correlated with any use of dietary supplements and colorectal tumor risk, and if they changed the hazard ratio by $\geq 10 \%$ using forward selection. The maximally adjusted model included age, sex, and number of colonoscopies during person time. 
Stratified analyses for the association of dietary supplement use and colorectal adenoma risk were conducted for MMR carriers with a history of colorectal neoplasms before study entry (recurrence), and for those without (first occurrence). To assess possible effect measure modification of associations between dietary supplement use and colorectal adenoma risk, we stratified our analysis for smoking status (never, former, current) and total fruit and vegetables intake (in quartiles: <179, 179-283, 283-387, $\geq 387 \mathrm{~g}$ /day). Nonusers, who never smoked, were defined as reference group to estimate HRs stratified for smoking status. In addition, nonusers who had a relatively low intake of fruit and vegetables of $<179 \mathrm{~g} /$ day, were defined as reference group to evaluate HRs stratified for total fruit and vegetables intake. To test for multiplicative interaction we used a log likelihood ratio test, comparing models for nonusers and users by smoking status and by strata of total fruit and vegetables intake.

A sensitivity analysis was performed for the association between any use and use of specific types of dietary supplements and

Table 1. General characteristics of the mismatch repair gene mutation carriers in the GEOLynch prospective cohort study.

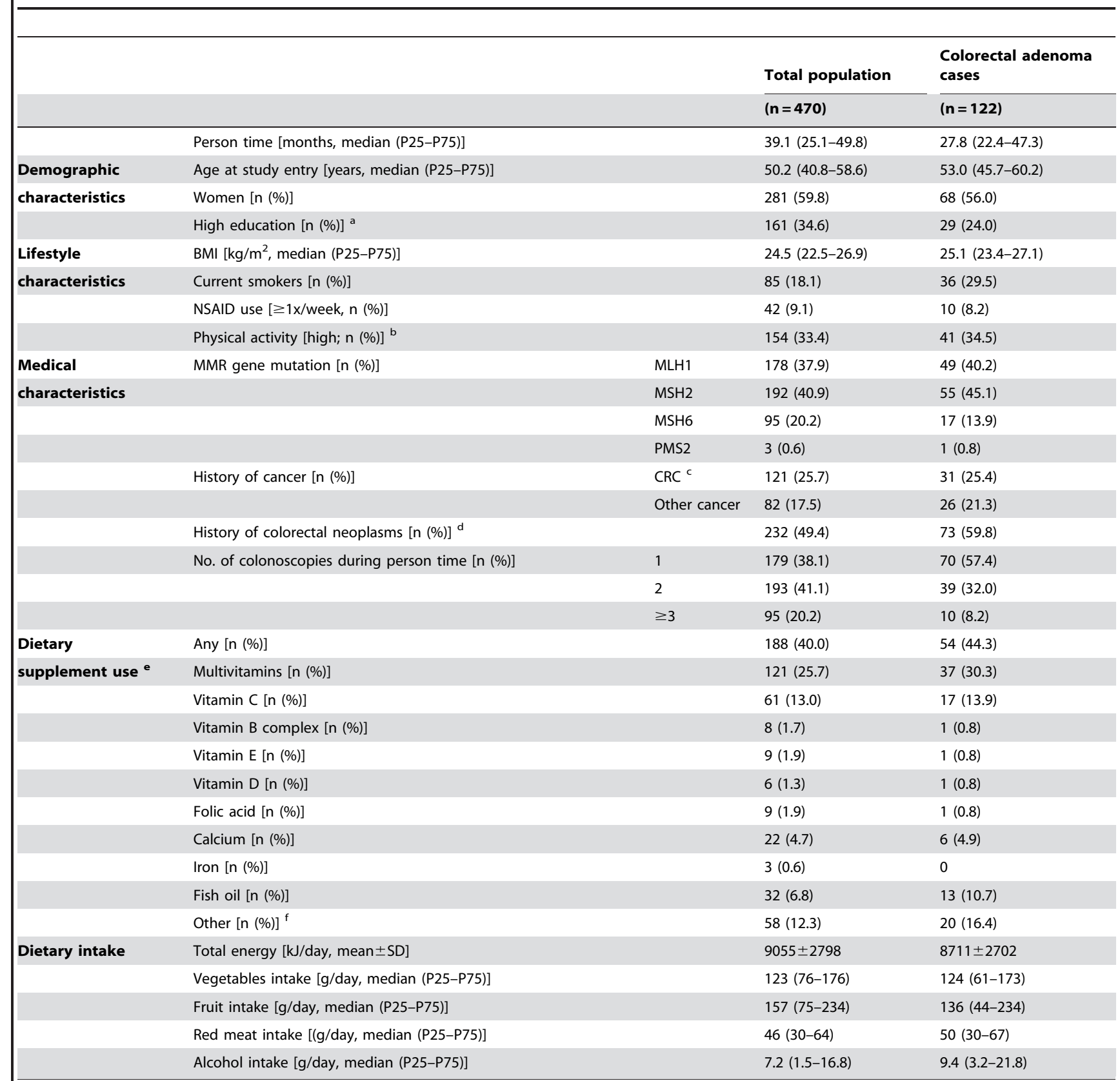

a College or university degree

b Highest tertile of the physical activity score

c CRC = colorectal cancer

d History of colorectal adenoma and/or carcinom

e Use of any dietary supplement during the last month

f E.g. glucosamine/chondroitin supplements, and garlic pills

doi:10.1371/journal.pone.0066819.t001 
colorectal adenoma risk, in which person time started at the time of assessment of dietary supplement use. $\mathrm{P}<0.05$ was considered statistically significant. All analyses were performed using SAS version 9.2 (SAS Institute Inc., Cary, NG).

\section{Results}

In this cohort of MMR gene mutation carriers, $122(26.0 \%)$ of 470 subjects developed a colorectal adenoma during an overall median person time of 39.1 months (table 1). The total person time was 18,449 person months. About $44 \%$ of the colorectal adenoma

Table 2. General characteristics of the mismatch repair gene mutation carriers stratified by dietary supplement use in the GEOLynch prospective cohort study.

\begin{tabular}{|c|c|c|c|c|c|}
\hline & & & \multicolumn{2}{|c|}{ Dietary supplement users } & \multirow{3}{*}{ p-value ${ }^{h}$} \\
\hline & & & \multirow{2}{*}{$\frac{\text { Users }^{a}}{(n=188)}$} & \multirow{2}{*}{$\begin{array}{l}\text { Nonusers }^{b} \\
(n=282)\end{array}$} & \\
\hline & & & & & \\
\hline & \multicolumn{2}{|l|}{ Person time [months, median (P25-P75)] } & $36.6(24.4-49.4)$ & $41.8(26.0-50.2)$ & 0.17 \\
\hline Demographic & \multicolumn{2}{|l|}{ Age at study entry [years, median (P25-P75)] } & $51.7(42.1-58.6)$ & $48.9(39.6-58.6)$ & 0.17 \\
\hline \multirow[t]{2}{*}{ characteristics } & \multicolumn{2}{|l|}{ Women [n (\%)] } & $128(68.1)$ & $153(54.3)$ & $<0.01$ \\
\hline & \multicolumn{2}{|l|}{ High education $[\mathrm{n}(\%)]^{\mathrm{c}}$} & $70(37.4)$ & $91(32.7)$ & 0.59 \\
\hline Lifestyle & \multicolumn{2}{|l|}{ BMI $\left[\mathrm{kg} / \mathrm{m}^{2}\right.$, median $\left.(\mathrm{P} 25-\mathrm{P} 75)\right]$} & $24.1(21.9-26.3)$ & $24.7(22.9-27.5)$ & 0.23 \\
\hline \multirow[t]{3}{*}{ characteristics } & \multicolumn{2}{|l|}{ Current smokers [n (\%)] } & $31(16.5)$ & $54(19.2)$ & 0.15 \\
\hline & \multicolumn{2}{|l|}{ NSAID use $[\geq 1 x /$ week, $n(\%)]$} & $17(9.2)$ & $25(9.1)$ & 0.97 \\
\hline & \multicolumn{2}{|l|}{ Physical activity [high; $n(\%){ }^{d}$} & $63(34.2)$ & 91 (32.9) & 0.76 \\
\hline Medical & MMR gene mutation [n (\%)] & MLH1 & $76(40.4)$ & $102(36.2)$ & 0.27 \\
\hline \multicolumn{2}{|l|}{ characteristics } & MSH2 & $66(35.1)$ & $126(44.7)$ & \\
\hline & & MSH6 & $43(22.9)$ & $52(18.4)$ & \\
\hline & & PMS2 & $2(1.1)$ & $1(0.4)$ & \\
\hline & \multicolumn{2}{|l|}{ Colorectal adenoma cases during follow up [n (\%)] } & $54(28.7)$ & $68(24.1)$ & 0.28 \\
\hline & History of cancer [n (\%)] & $\mathrm{CRC}^{\mathrm{e}}$ & $50(26.6)$ & $71(25.2)$ & 0.73 \\
\hline & & Other cancer & $41(21.8)$ & $41(14.5)$ & 0.04 \\
\hline & \multicolumn{2}{|l|}{ History of colorectal neoplasms [n (\%)] ${ }^{f}$} & $99(52.7)$ & $133(47.2)$ & 0.31 \\
\hline & No. of colonoscopies during person time [n (\%)] & 1 & $69(36.7)$ & $110(39.0)$ & 0.83 \\
\hline & & 2 & $80(42.6)$ & $113(40.1)$ & \\
\hline & & $\geq 3$ & $37(19.7)$ & $58(20.6)$ & \\
\hline Dietary & \multicolumn{2}{|l|}{ Multivitamins [n (\%)] } & $121(64.4)$ & - & \\
\hline supplement & \multicolumn{2}{|l|}{ Vitamin C [n (\%)] } & $61(32.5)$ & - & \\
\hline \multirow[t]{8}{*}{ use $^{\mathbf{a}}$} & \multicolumn{2}{|l|}{ Vitamin B complex [n (\%)] } & $8(4.3)$ & - & \\
\hline & \multicolumn{2}{|l|}{ Vitamin E [n (\%)] } & $9(4.8)$ & - & \\
\hline & \multicolumn{2}{|l|}{ Vitamin D [n (\%)] } & $6(3.2)$ & - & \\
\hline & \multicolumn{2}{|l|}{ Folic acid [n (\%)] } & $9(4.8)$ & - & \\
\hline & \multicolumn{2}{|l|}{ Calcium [n (\%)] } & $22(11.7)$ & - & \\
\hline & \multicolumn{2}{|l|}{ Iron [n (\%)] } & $3(1.6)$ & - & \\
\hline & \multicolumn{2}{|l|}{ Fish oil [n (\%)] } & $32(17.0)$ & - & \\
\hline & Other $[n(\%)]^{g}$ & & $58(30.9)$ & - & \\
\hline Dietary intake & Total energy intake $[\mathrm{kJ} /$ day, mean $\pm \mathrm{SD}]$ & & $8871 \pm 2647$ & $9179 \pm 2893$ & 0.36 \\
\hline & Vegetables intake [g/day, median (P25-P75)] & & $123(81-177)$ & $125(73-175)$ & 0.61 \\
\hline & Fruit intake [g/day, median (P25-P75)] & & $167(79-235)$ & $130(53-233)$ & 0.11 \\
\hline & Red meat intake [(g/day, median (P25-P75)] & & $46(27-63)$ & $46(34-64)$ & 0.38 \\
\hline & Alcohol intake [g/day, median (P25-P75)] & & $6.7(1.6-16.3)$ & $7.4(1.5-17.1)$ & 0.69 \\
\hline $\begin{array}{l}\text { a Use of any diet } \\
\text { b No use of dieta } \\
\text { c College or unive } \\
\text { d Highest tertile c } \\
\text { e CRC = colorecta } \\
\text { f History of colore } \\
\text { g E.g. glucosamin } \\
\text { h Calculated using } \\
\text { doi:10.1371/journ }\end{array}$ & $\begin{array}{l}\text { ry supplement during the last month } \\
\text { y supplement during the last month } \\
\text { rsity degree } \\
\text { f the physical activity score [31] } \\
\text { cancer } \\
\text { ctal adenoma and/or carcinoma } \\
\text { //chondroitin supplements, and garlic pills } \\
\text { Mann-Whitney U test for continuous variables } \\
\text { I.pone. } 0066819 . t 002\end{array}$ & categorical & variables & & \\
\hline
\end{tabular}


cases used a dietary supplement versus $40 \%$ in the total cohort. Colorectal adenoma cases were slightly older and lower educated compared to the total cohort. In addition, more persons smoked and alcohol intake was higher in colorectal adenoma cases compared to the total cohort.

Of the dietary supplement users, $28.7 \%$ developed a colorectal adenoma during the follow up period (table 2); this was $24.1 \%$ in nonusers. Compared to nonusers, dietary supplement users were slightly older, were more often women, were more often higher educated, smoked less often, had more often a history of cancer or colorectal tumors, and consumed more fruit.

Use of any dietary supplement was not statistically significantly associated with colorectal adenoma risk $(\mathrm{HR}=1.18$; 95\% CI 0.801.73) after adjustments for age, sex, and number of colonoscopies during person time (table 3). In addition, no associations were found between colorectal adenomas and multivitamin supplement use $(\mathrm{HR}=1.15 ; 95 \%$ CI $0.72-1.84)$, vitamin C supplement use $(\mathrm{HR}=1.57 ; \quad 95 \%$ CI $0.93-2.63)$, calcium supplement use (HR $=0.69 ; 95 \%$ CI 0.25-1.92), and supplements containing fish oil $(\mathrm{HR}=1.60 ; 95 \%$ CI $0.79-3.23)$.
In this study population, 73 of the 232 MMR carriers with a history of colorectal neoplasms before study entry developed a colorectal adenoma during follow up, of which 36 were dietary supplement user. In MMR carriers without a history of colorectal neoplasms $(\mathrm{n}=238), 49$ subjects developed a colorectal adenoma of which 18 subjects used a dietary supplement. Among MMR carriers with a history of colorectal neoplasms, dietary supplement use was not statistically significantly associated with colorectal adenoma risk $(\mathrm{HR}=0.87 ; 95 \%$ CI $0.44-1.75)$. However, a borderline statistically significantly increased risk was observed for dietary supplement use and colorectal adenoma risk among those without a history of colorectal neoplasms ( $\mathrm{HR}=1.60 ; 95 \%$ CI $0.98-2.60$ ).

Table 4 shows that there is no effect measure modification with smoking status ( $\mathrm{p}$ for multiplicative interaction: 0.41) and total fruit and vegetables intake ( $p$ for multiplicative interaction: 0.39 ) in the association of dietary supplement use and colorectal tumor risk. In a sensitivity analysis, in which person time started at the time of assessment of dietary supplement use, no differences in associations were observed for any use or use of specific types of dietary

Table 3. Association of dietary supplement use and colorectal adenoma risk in the GEOLynch prospective cohort study of MMR gene mutation carriers.

\begin{tabular}{|c|c|c|c|}
\hline \multicolumn{2}{|l|}{ Dietary supplement use } & $\begin{array}{l}\text { No use }{ }^{a} \\
\text { HR }\end{array}$ & $\begin{array}{l}\text { Use }^{b} \\
\text { HR }(95 \% \mathrm{Cl})\end{array}$ \\
\hline \multirow[t]{4}{*}{ Any dietary supplement } & No. of cases/non-cases & $68 / 214$ & $54 / 134$ \\
\hline & Person time (months, median) & 41.8 & 36.6 \\
\hline & $\mathrm{HR}$, adjusted for age \& sex & 1.0 & $1.21(0.85-1.72)$ \\
\hline & $\begin{array}{l}\text { HR, adjusted for age, sex, and number of } \\
\text { colonoscopies during person time }\end{array}$ & 1.0 & $1.18(0.80-1.73)$ \\
\hline \multirow[t]{4}{*}{ Multivitamins } & No. of cases/non-cases & $85 / 264$ & $37 / 84$ \\
\hline & Person time (months, median) & 39.6 & 37.5 \\
\hline & $H R$, adjusted for age \& sex & 1.0 & $1.38(0.93-2.07)$ \\
\hline & $\begin{array}{l}\text { HR, adjusted for age, sex, and number of } \\
\text { colonoscopies during person time }\end{array}$ & 1.0 & $1.15(0.72-1.84)$ \\
\hline \multirow[t]{4}{*}{ Vitamin C } & No. of cases/non-cases & $105 / 304$ & $17 / 44$ \\
\hline & Person time (months, median) & 39.9 & 34.5 \\
\hline & $\mathrm{HR}$, adjusted for age \& sex & 1.0 & $1.36(0.80-2.31)$ \\
\hline & $\begin{array}{l}\mathrm{HR} \text {, adjusted for age, sex, and number of } \\
\text { colonoscopies during person time }\end{array}$ & 1.0 & $1.57(0.93-2.63)$ \\
\hline \multirow[t]{4}{*}{ Calcium } & No. of cases/non-cases & $116 / 332$ & $6 / 16$ \\
\hline & Person time (months, median) & 39.2 & 36.9 \\
\hline & HR, adjusted for age \& sex & 1.0 & $0.68(0.24-1.93)$ \\
\hline & $\begin{array}{l}\mathrm{HR} \text {, adjusted for age, sex, and number of } \\
\text { colonoscopies during person time }\end{array}$ & 1.0 & $0.69(0.25-1.92)$ \\
\hline \multirow[t]{4}{*}{ Fish oil } & No. of cases/non-cases & $109 / 329$ & $13 / 19$ \\
\hline & Person time (months, median) & 39.2 & 37.1 \\
\hline & $\mathrm{HR}$, adjusted for age \& sex & 1.0 & $1.74(1.00-3.01)$ \\
\hline & $\begin{array}{l}\mathrm{HR} \text {, adjusted for age, sex, and number of } \\
\text { colonoscopies during person time }\end{array}$ & 1.0 & $1.60(0.79-3.23)$ \\
\hline
\end{tabular}

a No use of dietary supplements during the last month

b Use of any dietary supplement during the last month

doi:10.1371/journal.pone.0066819.t003 
Table 4. Association of any dietary supplement use and colorectal adenoma risk stratified for smoking status and total fruit and vegetables intake in the GEOLynch prospective cohort study of MMR gene mutation carriers.

\begin{tabular}{|c|c|c|c|c|}
\hline \multirow[b]{2}{*}{ Dietary supplement use } & \multicolumn{4}{|l|}{ Smoking status } \\
\hline & Never & Former & Current & \\
\hline \multicolumn{5}{|l|}{ No use ${ }^{a}$} \\
\hline No. of cases/non-cases & $17 / 99$ & $28 / 83$ & $23 / 31$ & \\
\hline Person time (months, median) & 46.0 & 44.9 & 31.0 & \\
\hline $\begin{array}{l}\mathrm{HR}(95 \% \mathrm{Cl}) \text { adjusted for age, sex, and number of } \\
\text { colonoscopies during person time }\end{array}$ & 1.0 & $1.54(0.84-2.84)$ & $2.54(1.42-4.54)$ & \\
\hline \multicolumn{5}{|l|}{ Use $^{b}$} \\
\hline No. of cases/non-cases & $8 / 56$ & $33 / 60$ & $13 / 18$ & \\
\hline Person time (months, median) & 37.2 & 35.9 & 39.1 & \\
\hline $\begin{array}{l}\mathrm{HR}(95 \% \mathrm{Cl}) \text { adjusted for age, sex, and number of } \\
\text { colonoscopies during person time }\end{array}$ & $0.89(0.39-2.00)$ & $2.05(1.10-3.82)$ & $3.37(1.59-7.13)$ & \\
\hline \multirow[t]{2}{*}{ P for multiplicative interaction } & & & & 0.41 \\
\hline & \multicolumn{4}{|c|}{ Total fruit and vegetables intake (g/day) } \\
\hline Dietary supplement use & $<179$ & 179-283 & 283-387 & $\geq 387$ \\
\hline \multicolumn{5}{|l|}{ No use ${ }^{a}$} \\
\hline No. of cases/non-cases & $26 / 51$ & $10 / 60$ & $15 / 51$ & $18 / 51$ \\
\hline Person time (months, median) & 34.3 & 45.9 & 45.3 & 36.8 \\
\hline $\begin{array}{l}\mathrm{HR}(95 \% \mathrm{Cl}) \text { adjusted for age, sex, and number of } \\
\text { colonoscopies during person time }\end{array}$ & 1.0 & $0.48(0.23-1.03)$ & $0.88(0.44-1.74)$ & $0.78(0.45-1.35)$ \\
\hline \multicolumn{5}{|l|}{ Use $^{b}$} \\
\hline No. of cases/non-cases & $16 / 25$ & $13 / 34$ & $14 / 38$ & $14 / 34$ \\
\hline Person time (months, median) & 27.2 & 42.1 & 40.3 & 35.9 \\
\hline $\begin{array}{l}\mathrm{HR}(95 \% \mathrm{Cl}) \text { adjusted for age, sex, and number of } \\
\text { colonoscopies during person time }\end{array}$ & $1.25(0.63-2.52)$ & $0.97(0.45-2.08)$ & $0.96(0.45-2.03)$ & $0.66(0.29-1.50)$ \\
\hline P for multiplicative interaction & & & & 0.39 \\
\hline
\end{tabular}

supplements and colorectal adenoma risk. However, a borderline statically significantly increased risk of colorectal adenomas was observed for persons who took supplements containing fish oil $(\mathrm{HR}=1.78 ; 95 \%$ CI $0.92-3.45)$.

\section{Discussion}

The present study did not observe a statistically significant association between use of any dietary supplement and colorectal adenoma risk among individuals with Lynch syndrome. No marked associations were found for multivitamin supplement use, vitamin $\mathrm{C}$ supplement use, calcium supplement use, and use of supplements containing fish oil and colorectal adenoma risk either.

To our best knowledge, this is the first prospective cohort study that examined the association of dietary supplement use and development of colorectal adenomas in individuals with Lynch syndrome. The association between dietary supplement use and sporadic colorectal adenoma risk in the general population has been investigated in many epidemiological studies. [23-27] Our findings for dietary supplement use and colorectal adenoma risk in individuals with Lynch syndrome were largely consistent with findings in the general population. Calcium supplement use might contribute to a lower risk of colorectal adenomas in the general population. [27] However, no evidence of association was found for calcium supplement use and colorectal adenoma risk in this Lynch syndrome population. A randomized, double-blind, placebo-controlled trial with calcium supplements, conducted in 30 first-degree relatives of Lynch syndrome patients, showed a small but nonstatistically significant reduction in epithelial cell proliferation in biopsies of the rectum, and no effect in the sigmoid and descending colon compared with placebo after 12 weeks of intervention. [32] Those results also do not suggest that the use of calcium supplements may help to lower the increased risk of colorectal adenoma occurrence among mismatch repair gene carriers.

No significant association was shown for fish oil supplements and colorectal adenoma risk, when person time started at the date of the most recent colonoscopy before assessment of dietary supplement use. However, according to sensitivity analyses when person time started at the time of assessment of dietary supplement use, a borderline statistically significantly increased risk for colorectal adenomas was observed for Lynch syndrome patients who took fish oil supplements. Our findings should be interpreted with caution, as our hazard ratios appear to be unstable, probably due to the low number of fish oil supplement users in our study. Moreover, the possible detrimental role of supplements containing fish oil on colorectal tumor risk in Lynch syndrome patients contrasts with findings in the general population: fish oil, and then particularly n-3 PUFA from fish oil, are thought to play a 
beneficial role in the prevention of colorectal cancer due to its antiangiogenic and anti-inflammatory properties and its regulatory role in cell proliferation and apoptosis. [33-36] Nevertheless, the potentially increased risk for developing colorectal adenomas due to supplements containing fish oil in our study corresponds with findings in a nested case-control study within the VITamins And Lifestyle cohort. High intake of n-3 PUFA from diet plus supplements was associated with a decreased risk of colorectal cancer among those at low genetic risk $(\mathrm{HR}=0.23 ; 95 \% \mathrm{CI}$ : $0.07-0.78$ ), while such intake was associated with a substantially increased risk among those at high genetic risk $(\mathrm{HR}=5.79 ; 95 \%$ CI: 1.79-18.7). Genetic risk was calculated using a genetic risk score enumerating the number of risk alleles present at 16 single nucleotide polymorphisms (SNPs) located within known/recentlyidentified CRC susceptibility loci (Personal communication, Elizabeth Kantor). Expansion of our Lynch syndrome cohort and a longer follow up are essential to further investigate the role of fish oil supplements and colorectal adenoma risk.

Stratified analyses for MMR carriers with and without a history of colorectal neoplasms before study entry showed no association for dietary supplement use and colorectal adenoma risk among those without a history of colorectal neoplasms, whereas a borderline statistically significantly increased risk was observed for MMR carriers with a history of colorectal neoplasms. Due to the low number of users reflected in the wide confidence intervals in this study, we are not able to draw firm conclusions considering differences between these two groups.

Several critical points regarding the study design and dietary supplement use need to be highlighted. The combined analysis of all the different kinds of dietary supplements on colorectal adenoma risk may mask individual effects of each nutrient supplement. Although this study is the largest prospective study in MMR gene mutation carriers up until now, the small number of users of individual dietary supplements in our study narrows the extent to which we can observe associations.

MMR gene mutation carriers might have increased their dietary supplement intake based on their health status and risk, [28] and may therefore have a higher use of dietary supplements compared to the general Dutch population. However, dietary supplement use in this Lynch syndrome population was similar (40\%) to the general Dutch population (30-56\%); also in our study dietary supplement users were more often women. [37] Moreover, we relied on self-reporting which makes misclassification of dietary

\section{References}

1. Lynch HT, Lynch PM, Lanspa SJ, Snyder CL, Lynch JF, et al. (2009) Review of the Lynch syndrome: history, molecular genetics, screening, differential diagnosis, and medicolegal ramifications. Clin Genet 76: 1-18.

2. Barrow E, Alduaij W, Robinson L, Shenton A, Clancy T, et al. (2008) Colorectal cancer in HNPCC: cumulative lifetime incidence, survival and tumour distribution. A report of 121 families with proven mutations. Clin Genet 74: 233-242.

3. Hampel H, Stephens JA, Pukkala E, Sankila R, Aaltonen LA, et al. (2005) Cancer risk in hereditary nonpolyposis colorectal cancer syndrome: later age of onset. Gastroenterology 129: 415-421.

4. Quehenberger F, Vasen HF, van Houwelingen HC (2005) Risk of colorectal and endometrial cancer for carriers of mutations of the hMLH1 and hMSH2 gene: correction for ascertainment. J Med Genet 42: 491-496.

5. Jenkins MA, Baglietto L, Dowty JG, Van Vliet CM, Smith L, et al. (2006) Cancer risks for mismatch repair gene mutation carriers: a population-based early onset case-family study. Clin Gastroenterol Hepatol 4: 489-498.

6. Kempers MJ, Kuiper RP, Ockeloen CW, Chappuis PO, Hutter P, et al. (2011) Risk of colorectal and endometrial cancers in EPCAM deletion-positive Lynch syndrome: a cohort study. Lancet Oncol 12: 49-55.

7. Kuiper RP, Vissers LE, Venkatachalam R, Bodmer D, Hoenselaar E, et al. (2011) Recurrence and variability of germline EPCAM deletions in Lynch syndrome. Hum Mutat 32: 407-414.

8. de la Chapelle A (2005) The incidence of Lynch syndrome. Fam Cancer 4: 233237. supplement use possible. However, according to several studies, self-reported dietary supplement use is a reliable method to measure intake of dietary supplements. [38-40] Thus, dietary supplement use in individuals with Lynch syndrome included in this study reflects use in the general Dutch population and is a reliable indicator for the actual intake.

As information on dosage and duration was not assessed, we could not calculate the total nutrient intake by foods and dietary supplements together, and were unable to examine changes in dietary supplement use over time. Our data only allowed us to examine the associations for dietary supplement use as it was reported before the events of interest.

Strengths of this study are the inclusion of confirmed MMR gene mutation carriers in our cohort, and the high participation rate of $73 \%$. These factors make our findings generalizable to Lynch syndrome patients in comparable clinical settings. Other strengths are the prospective cohort design, the relatively long person time, and the ability to adjust for many potential confounders.

In conclusion, in this prospective cohort study no associations between dietary supplement use and colorectal adenoma risk among individuals with Lynch syndrome were indicated. Further research is warranted to determine whether or not dietary supplement use is associated to colorectal adenoma and colorectal cancer risk in MMR gene mutation carriers.

\section{Acknowledgments}

We are indebted to all study participants for their cooperation. The authors thank Mary Velthuizen and Alice Donselaar (Netherlands Foundation for the Detection of Hereditary Tumors), Maria van Vugt (Radboud University Nijmegen Medical Center), and Leontien Witjes (Wageningen University) for assistance with participant recruitment and data collection. The medical specialists of the participants are gratefully acknowledged for their collaboration.

\section{Author Contributions}

Conceived and designed the experiments: EK HV FN JK. Performed the experiments: AB AJ RHB HV FN JK. Analyzed the data: RHB RW FvD $\mathrm{AB}$ AJ EK. Contributed reagents/materials/analysis tools: RHB RW FvD $\mathrm{AB}$ AJ EK. Wrote the paper: RHB RW EK. Revising the article for important intellectual content: AB FvD AJ JK FN HV. Obtained funding: EK FN HV. Administrative support: AB AJ RHB HV FN JK. Study supervision: EK.
9. Hampel H, Frankel WL, Martin E, Arnold M, Khanduja K, et al. (2008) Feasibility of screening for Lynch syndrome among patients with colorectal cancer. J Clin Oncol 26: 5783-5788.

10. Rijcken FE, Hollema H, Kleibeuker JH (2002) Proximal adenomas in hereditary non-polyposis colorectal cancer are prone to rapid malignant transformation. Gut 50: 382-386.

11. De Jong AE, Morreau H, Van Puijenbroek M, Eilers PH, Wijnen J, et al. (2004) The role of mismatch repair gene defects in the development of adenomas in patients with HNPCC. Gastroenterology 126: 42-48.

12. Signaleringscommissie Kanker van KWF Kankerbestrijding (2007). Signaleringsrapport 'De kans op kanker'. Bewerking van cijfers NKR en CBS 19992003. Amsterdam, the Netherlands.

13. American Cancer Society (2008). Colorectal Cancer Facts \& Figures 2008-2010. Atlanta.

14. Jarvinen HJ, Aarnio M, Mustonen H, Aktan-Collan K, Aaltonen LA, et al. (2000) Controlled 15-year trial on screening for colorectal cancer in families with hereditary nonpolyposis colorectal cancer. Gastroenterology 118: 829-834.

15. Vasen HF, Abdirahman M, Brohet R, Langers AM, Kleibeuker JH, et al. (2010) One to 2-year surveillance intervals reduce risk of colorectal cancer in families with Lynch syndrome. Gastroenterology 138: 2300-2306.

16. (2008) Erfelijke darmkanker - Landelijke richtlijn - Versie 1. Vereniging Klinische Genetica Nederland. 
17. Botma A, Nagengast FM, Braem MG, Hendriks JC, Kleibeuker JH, et al. (2010) Body mass index increases risk of colorectal adenomas in men with Lynch syndrome: the GEOLynch cohort study. J Clin Oncol 28: 4346-4353.

18. Winkels RM, Botma A, Van Duijnhoven FJ, Nagengast FM, Kleibeuker JH, et al. (2011) Smoking Increases the Risk for Colorectal Adenomas in Patients With Lynch Syndrome. Gastroenterology.

19. Botma A, Vasen HF, van Duijnhoven FJ, Kleibeuker JH, Nagengast FM, et al. (2013) Dietary patterns and colorectal adenomas in Lynch syndrome: The GEOLynch cohort study. Cancer 119: 512-521.

20. Diergaarde B, Braam H, Vasen HF, Nagengast FM, van Muijen GN, et al. (2007) Environmental factors and colorectal tumor risk in individuals with hereditary nonpolyposis colorectal cancer. Clin Gastroenterol Hepatol 5: 736742.

21. McGinnis JM, Birt DF, Brannon PM, Carroll RJ, Gibbons RD, et al. (2007) National institutes of health state-of-the-science conference statement: Multivitamin/mineral supplements and chronic disease prevention. American Journal of Clinical Nutrition 85: 257s-264s.

22. Ervin RB, Wright JD, Kennedy-Stephenson J (1999) Use of dietary supplements in the United States, 1988-94. Vital Health Stat 11: i-iii, 1-14.

23. Neugut AI, Horvath K, Whelan RL, Terry MB, Garbowski GC, et al. (1996) The effect of calcium and vitamin supplements on the incidence and recurrence of colorectal adenomatous polyps. Cancer 78: 723-728.

24. Figueiredo JC, Mott LA, Giovannucci E, Wu KN, Cole B, et al. (2011) Folic acid and prevention of colorectal adenomas: a combined analysis of randomized clinical trials. International Journal of Cancer 129: 192-203.

25. Bjelakovic G, Nagorni A, Nikolova D, Simonetti RG, Bjelakovic M, et al. (2006) Meta-analysis: antioxidant supplements for primary and secondary prevention of colorectal adenoma. Alimentary Pharmacology \& Therapeutics 24: 281-291.

26. Papaioannou D, Cooper KL, Carroll C, Hind D, Squires H, et al. (2011) Antioxidants in the chemoprevention of colorectal cancer and colorectal adenomas in the general population: a systematic review and meta-analysis. Colorectal Disease 13: 1085-1099.

27. Weingarten MA, Zalmanovici A, Yaphe J (2008) Dietary calcium supplementation for preventing colorectal cancer and adenomatous polyps. Cochrane Database of Systematic Reviews.
28. Carroll C, Booth A, Cooper K (2011) A worked example of "best fit" framework synthesis: A systematic review of views concerning the taking of some potential chemopreventive agents. Bmc Medical Research Methodology 11.

29. Feunekes GI, Van Staveren WA, De Vries JH, Burema J, Hautvast JG (1993) Relative and biomarker-based validity of a food-frequency questionnaire estimating intake of fats and cholesterol. Am J Clin Nutr 58: 489-496.

30. Verkleij-Hagoort AC, de Vries JH, Stegers MP, Lindemans J, Ursem NT, et al. (2007) Validation of the assessment of folate and vitamin B12 intake in women of reproductive age: the method of triads. Eur J Clin Nutr 61: 610-615.

31. Pols MA, Peeters PH, Bueno-De-Mesquita HB, Ocke MC, Wentink CA, et al. (1995) Validity and repeatability of a modified Baecke questionnaire on physical activity. Int J Epidemiol 24: 381-388.

32. Cats A, Kleibeuker JH, van der Meer R, Kuipers F, Sluiter WJ, et al. (1995) Randomized, double-blinded, placebo-controlled intervention study with supplemental calcium in families with hereditary nonpolyposis colorectal cancer. J Natl Cancer Inst 87: 598-603.

33. Reddy BS (2004) Omega-3 fatty acids in colorectal cancer prevention. Int J Cancer 112: 1-7.

34. Calviello G, Serini S, Piccioni E (2007) n-3 polyunsaturated fatty acids and the prevention of colorectal cancer: molecular mechanisms involved. Curr Med Chem 14: 3059-3069.

35. Schottenfeld D, Beebe-Dimmer J (2006) Chronic inflammation: a common and important factor in the pathogenesis of neoplasia. CA Cancer J Clin 56: 69-83.

36. Rose DP, Connolly JM (1999) Omega-3 fatty acids as cancer chemopreventive agents. Pharmacol Ther 83: 217-244.

37. Van Rossum CTM, Fransen HP, Verkaik-Kloosterman J, Buurma-Rethans EJM, Ocke MC (2011) Dutch National Food Consumption Survey 2007-2010 Diet of children and adults aged 7 to 69 years. Bilthoven: National Institute for Public Health and the Environment.

38. Satia-Abouta J, Patterson RE, King IB, Stratton KL, Shattuck AL, et al. (2003) Reliability and validity of self-report of vitamin and mineral supplement use in the vitamins and lifestyle study. Am J Epidemiol 157: 944-954.

39. Patterson RE, Kristal AR, Levy L, McLerran D, White E (1998) Validity of methods used to assess vitamin and mineral supplement use. Am J Epidemiol 148: 643-649.

40. Block G, Sinha R, Gridley G (1994) Collection of dietary-supplement data and implications for analysis. Am J Clin Nutr 59: 232S-239S. 